\title{
Cellular effects and delivery propensity of penetratin is influenced by conjugation to parathyroid hormone fragment 1-34 in synergy with $\mathrm{pH}$
}

Kristensen, Mie; Nielsen, Line Hagner; Zor, Kinga; Boisen, Anja; Christensen, Malene Vinther; Berthelsen, Jens; Mørck Nielsen, Hanne

Published in:

Bioconjugate Chemistry

Link to article, DOI:

10.1021/acs.bioconjchem.7b00687

Publication date:

2018

Document Version

Peer reviewed version

Link back to DTU Orbit

Citation (APA):

Kristensen, M., Nielsen, L. H., Zor, K., Boisen, A., Christensen, M. V., Berthelsen, J., \& Mørck Nielsen, H. (2018). Cellular effects and delivery propensity of penetratin is influenced by conjugation to parathyroid hormone fragment 1-34 in synergy with $\mathrm{pH}$. Bioconjugate Chemistry, 29(2), 371-381.

https://doi.org/10.1021/acs.bioconjchem.7b00687

\section{General rights}

Copyright and moral rights for the publications made accessible in the public portal are retained by the authors and/or other copyright owners and it is a condition of accessing publications that users recognise and abide by the legal requirements associated with these rights.

- Users may download and print one copy of any publication from the public portal for the purpose of private study or research.

- You may not further distribute the material or use it for any profit-making activity or commercial gain

- You may freely distribute the URL identifying the publication in the public portal 


\section{RCBioconjugate Chemistry}

\section{Article}

Subscriber access provided by DTU Library

\section{Cellular effects and delivery propensity of penetratin is influenced by conjugation to parathyroid hormone fragment 1-34 in synergy with $\mathrm{pH}$}

Mie Kristensen, Line Hagner Nielsen, Kinga Zór, Anja Boisen, Malene

Vinther Christensen, Jens Berthelsen, and Hanne Mørck Nielsen

Bioconjugate Chem., Just Accepted Manuscript • DOI: 10.1021/acs.bioconjchem.7b00687 • Publication Date (Web): 20 Nov 2017

Downloaded from http://pubs.acs.org on December 20, 2017

\section{Just Accepted}

"Just Accepted" manuscripts have been peer-reviewed and accepted for publication. They are posted online prior to technical editing, formatting for publication and author proofing. The American Chemical Society provides "Just Accepted" as a free service to the research community to expedite the dissemination of scientific material as soon as possible after acceptance. "Just Accepted" manuscripts appear in full in PDF format accompanied by an HTML abstract. "Just Accepted" manuscripts have been fully peer reviewed, but should not be considered the official version of record. They are accessible to all readers and citable by the Digital Object Identifier (DOI®). "Just Accepted" is an optional service offered to authors. Therefore, the "Just Accepted" Web site may not include all articles that will be published in the journal. After a manuscript is technically edited and formatted, it will be removed from the "Just Accepted" Web site and published as an ASAP article. Note that technical editing may introduce minor changes to the manuscript text and/or graphics which could affect content, and all legal disclaimers and ethical guidelines that apply to the journal pertain. ACS cannot be held responsible for errors or consequences arising from the use of information contained in these "Just Accepted" manuscripts. 
Cellular Effects and Delivery Propensity of Penetratin is Influenced by Conjugation to Parathyroid Hormone Fragment 1-34 in Synergy with pH

Mie Kristensen ${ }^{1}$, Line Hagner Nielsen ${ }^{2 \ltimes}$, Kinga Zor ${ }^{2 \ltimes}$, Anja Boisen ${ }^{2}$, Malene Vinter Christensen ${ }^{3}$, Jens Berthelsen $^{4}$, Hanne Mørck Nielsen ${ }^{1 *}$

${ }^{1}$ Section for Biologics, Department of Pharmacy, Faculty of Health and Medical Sciences, University of Copenhagen, Universitetsparken 2, DK-2100 Copenhagen, Denmark

${ }^{2}$ Department of Micro- and Nanotechnology, Technical University of Denmark, Ørsteds Plads 345C, DK2800 Kgs. Lyngby, Denmark

${ }^{3}$ Department of Drug Design and Pharmacology, Faculty of Health and Medical Sciences, University of Copenhagen, Universitetsparken 2, DK-2100 Copenhagen, Denmark

${ }^{4}$ Department of International Health, Immunology and Microbiology, Faculty of Health and Medical Sciences, University of Copenhagen, Blegdamsvej 3, DK-2200 Copenhagen, Denmark

a Contributed equally to the work

*Corresponding author: Hanne Mørck Nielsen, Department of Pharmacy, Faculty of Health and Medical Sciences, Universitetsparken 2, DK-2100 Copenhagen Ø, Denmark. Tel.: +45 35336063 , Correspondence: hanne.morck@sund.ku.dk 


\section{ABSTRACT}

The cell-penetrating peptide (CPP) penetratin, has demonstrated potential as a carrier for transepithelial delivery of cargo peptides, such as the therapeutically relevant part of parathyroid hormone, i.e. PTH(1-34). The purpose of the present study was to elucidate the relevance of $\mathrm{pH}$ for $\mathrm{PTH}(1-34)$-penetratin conjugates and for co-administered penetratin with $\mathrm{PTH}(1-34)$ in terms of transepithelial permeation of $\mathrm{PTH}(1-34)$ and cellular effects. Transepithelial permeation was assessed using monolayers of the Caco-2 cell culture model, and effects on Caco-2 cellular viability kinetics were evaluated by using the Real-Time-GLO assay as well as by microscopy following Tryphan blue staining. Morphological Caco-2 cell changes were studied exploiting the impedance-based xCELLigence system as well as optically using the oCelloscope setup. Finally, the effect of $\mathrm{pH}$ on the folding propensity of the $\mathrm{PTH}(1-34)$-penetratin conjugate and its ability to disrupt lipid membranes were assessed by circular dichroism (CD) spectroscopy and the calcein release assay, respectively. The transepithelial $\mathrm{PTH}(1-34)$ permeation was not $\mathrm{pH}$-dependent when applying the coadministration approach. However, by applying the conjugation approach, the $\mathrm{PTH}(1-34)$ permeation was significantly enhanced by lowering the $\mathrm{pH}$ from 7.4 to 5 , but also associated with a compromised barrier and a lowering of the cellular viability. The negative effects on the cellular viability following cellular incubation with the PTH(1-34)-penetratin conjugate were moreover confirmed during real-time monitoring of the Caco2 cell viability as well as by enhanced Tryphan blue uptake. In addition, morphological changes were primarily observed for cells incubated with the $\mathrm{PTH}(1-34)$-penetratin conjugate at $\mathrm{pH} 5$, which was moreover demonstrated to have an enhanced membrane permeating effect following lowering of the $\mathrm{pH}$ from 7.4 to 5 . The latter observation was, however, not a result of better secondary folding propensity at $\mathrm{pH} 5$ when compared to $\mathrm{pH}$ 7.4. 


\section{INTRODUCTION}

Peptide drug entities are of high therapeutic interest due to their potency and specific mode of action, and an increasing number of these drugs currently enter production lines in the pharmaceutical industry. A major obstacle in the successful implementation of peptide drugs, and biopharmaceuticals in general, is that their administration to a large extent is limited to invasive routes; often experienced as inconvenient and potentially leading to poor patient compliance. When pharmacologically relevant, oral administration of a peptide drug may thus, be pursued. However, sufficient delivery of peptide drugs via the gastrointestinal tract is limited by poor enzymatic stability and large molecular size, the latter hindering non-aided permeation across the intestinal epithelium. Nevertheless, the class of membrane interacting peptides termed cell-penetrating peptides (CPPs) has demonstrated promising potential as carriers for transepithelial delivery of cargo peptides. ${ }^{1}$ In order to enhance the transepithelial permeation of a cargo peptide using CPPs, coadministration with a CPP in a physical mixture ${ }^{2-4}$ or conjugation to a $\mathrm{CPP}^{5}$ may be pursued. ${ }^{6}$ The latter approach ensures an inherent proximity of the two molecules, but may negatively affect the biological activity of the therapeutic cargo as well as the delivery propensity of the CPP. On the other hand, by using the co-administration approach one may obtain a pool of poorly defined CPP-cargo complexes due to electrostatic and/or hydrophobic interactions between the CPP and the cargo moiety. A previous study demonstrated that conjugation of the CPP, penetratin, to the biologically active part of parathyroid hormone (PTH(1-34)) negatively affected the potency of PTH(1-34). ${ }^{7}$ In addition, the ability of penetratin to enhance $\mathrm{PTH}(1-34)$ permeation across an intestinal epithelium in vitro was more effective when co-administered with PTH(1-34) as compared to covalently conjugated to $\mathrm{PTH}(-34)$ at the same molar ratios. ${ }^{8}$ Using the coadministration approach, a number of previous reports suggest that intermolecular electrostatic CPP-cargo interactions as well as the strength of the interaction are essential in order to obtain CPP-mediated transepithelial permeation of a cargo peptide. ${ }^{9-11}$ In addition, a recent study questions whether complex formation between insulin and penetratin is a necessity to obtain penetratin-mediated transepithelial insulin permeation. ${ }^{12}$ That study demonstrated that despite using a $\mathrm{pH}$ higher than the $\mathrm{pI}$ of the cargo (namely $\mathrm{pH} 6.5$ and 7.4) for induction of high levels of electrostatic interactions between insulin and the CPP, no transepithelial penetratin-mediated insulin permeation in vitro was evident. On the contrary, at $\mathrm{pH} 5$, at which insulin-penetratin complexation did not dominate the sample, co-administration of penetratin with insulin significantly, and without signs of detrimental effects on the epithelial cells, improved the transepithelial insulin permeation when compared to insulin administered alone under the same conditions. Importantly, pH-lowering compounds are frequently implemented in drug delivery systems as a feasible strategy to improve the transmucosal delivery of peptide and protein-drug entities by limiting the enzymatic degradation at the absorption site ${ }^{13-15}$ (reviewed in ${ }^{16,17}$ ); thus demonstrating the relevance of studying the impact of applying a slightly acidic $\mathrm{pH}$ for improving oral delivery. 
Thus, to mechanistically explain the influence of $\mathrm{pH}$ and administration approach, the aim of this study was to conduct in-depth investigations to explore cellular and membrane effects of applying pH 5 and 7.4 for penetratin-enhanced transepithelial $\mathrm{PTH}(1-34)$ permeation across epithelial cell layers; focusing on potentially associated toxic events induced by using the conjugation approach versus the co-administration approach.

\section{RESULTS}

\section{CPP-mediated transepithelial PTH(1-34) permeation depends on administration approach and pH}

Penetratin was successfully conjugated to $\mathrm{PTH}(1-34)^{8}$ resulting in a molecule with higher molecular weight and $\mathrm{pI}$ than the PTH(1-34). The sequences, molecular weights, and $\mathrm{pI}$ values for $\mathrm{PTH}(1-34)$, penetratin, and the PTH(1-34)-penetratin conjugate are listed in Table 1.

Table 1. Sequences of PTH(1-34), penetratin and PTH(1-34)-penetratin

\begin{tabular}{|l|l|l|l|}
\hline Name & Sequence & Mw (Da) & pI \\
\hline PTH(1-34) & SVSEIQLMHNLGKHLNSMERVEWLRKKLQDVHNF & 4117.6 & 8.3 \\
\hline Penetratin & RQIKIWFQNRRMKWKK & 2245.8 & 12.3 \\
\hline PTH(1-34)-penetratin & $\begin{array}{l}\text { S*SVSEIQLMHNLGKHLNSMERVEWLRKKLQDVHNF } \\
\text { RQIKIWFQNRRMKWKK }\end{array}$ & 6433.6 & 11.1 \\
\hline
\end{tabular}

*N-terminal serine (S) residue left on the amino acid sequence encoding PTH(1-34)-penetratin after the histidine tag was cleaved off. Theoretical molecular weight values are obtained from Expasy.org.

PTH(1-34) conjugated to penetratin or co-administered with penetratin in a 1:1 molar ratio were evaluated for its ability to permeate Caco-2 cell monolayers at $\mathrm{pH} 7.4$ or $\mathrm{pH} 5$ in order to investigate the effect of lowering the $\mathrm{pH}$. At $\mathrm{pH}$ 7.4, the co-administration approach was significantly more effective than the conjugation approach with respect to enhancing the transepithelial PTH(1-34) permeation (Figure 1a). Lowering the $\mathrm{pH}$ of the $\mathrm{PTH}(1-34)$-penetratin conjugate from 7.4 to 5 increased the $\mathrm{PTH}(1-34)$ permeation 3.1-fold and to the same level as if co-administered (Figure 1b) as also reflected in the calculated $\mathrm{P}_{\text {app }}$ values (Table 2). In contrast, lowering the $\mathrm{pH}$ from 7.4 to 5 for PT H(1-34) co-administered with penetratin resulted in only a 1.4-fold increase in the amount of permeated PTH(1-34) (Table 2). 

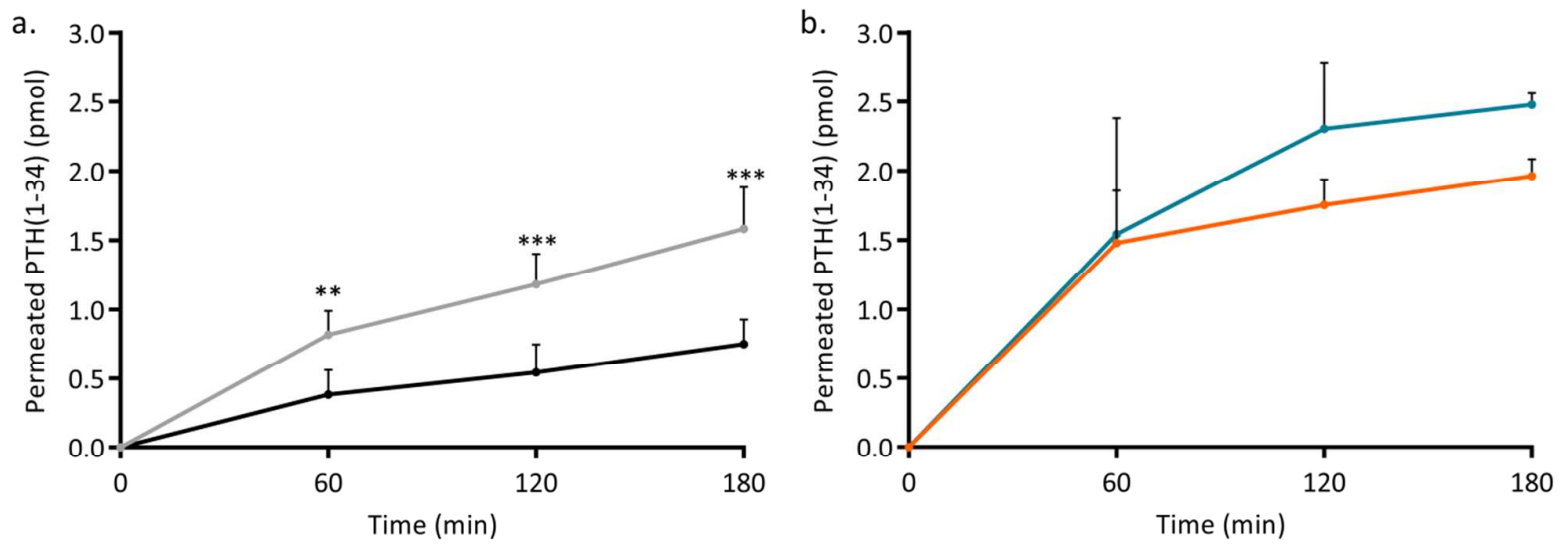

Figure 1. Permeation of PTH(1-34) after application of $40 \mu \mathrm{M}$ PTH(1-34)-penetratin conjugate or $40 \mu \mathrm{M}$ PTH(1-34) co-administered with penetratin (molar ratio 1:1) at pH 7.4 (a) or pH 5 (b). Data are presented as mean \pm SEM $(\mathrm{n}=6, \mathrm{~N}=2)$. Grey: PTH(1-34) + penetratin $\mathrm{pH} 7.4$, black: PTH(1-34)-penetratin $\mathrm{pH} 7.4$, orange: $\mathrm{PTH}(1-34)$-penetratin $\mathrm{pH}$ 5, blue: $\mathrm{PTH}(1-34)+$ penetratin $\mathrm{pH}$ 5. Levels of significance are **: $\mathrm{p}<0.01, * * *: \mathrm{p}<0.001$.

Table 2. The apparent permeability coefficient $\left(\mathrm{P}_{\mathrm{app}}\right)$ determined after application of $40 \mu \mathrm{M}$ PTH(1-34)penetratin fusion peptide or similar total concentrations of $\mathrm{PTH}(1-34)$ co-administered with penetratin (ratio 1:1) at pH 7.4 or 5 across Caco-2 monolayers. Data are based on calculations to the end-point and presented as mean $\pm \operatorname{SEM}(n=6, N=2)$.

\begin{tabular}{|l|c|c|}
\hline & \multicolumn{2}{|c|}{ P $_{\text {app }}\left(\mathbf{1 0}^{-9} \mathbf{c m} / \mathbf{s}\right)$} \\
\hline Test sample & pH 7.4 & pH 5 \\
\hline PTH(1-34) + penetratin & $3.4 \pm 0.6$ & $4.7 \pm 1.4$ \\
\hline PTH(1-34)-penetratin & $1.5 \pm 0.5$ & $4.6 \pm 0.2$ \\
\hline
\end{tabular}

Only for the conjugate, decreasing the $\mathrm{pH}$ negatively affects epithelial integrity and cellular viability

In order to evaluate the integrity of the Caco-2 cell monolayers and potential cytotoxicity resulting from exposure to $\mathrm{PTH}(1-34)$ and penetratin as either co-administered or conjugated, the TEER was determined before and after each permeation study (Figure 2a), and the cellular viability was evaluated after each permeation study (Figure 2b).

Neither of the $\mathrm{pH} 7.4$ samples affected the integrity of the epithelium or the cellular viability, whereas lowering the $\mathrm{pH}$ to 5 resulted in a significant decrease in both epithelial integrity and cellular viability as a result of incubation with the PTH(1-34)-penetratin conjugate. Thus, the observed increase in PTH(1-34) permeation as a result of lowering the $\mathrm{pH}$ of the $\mathrm{PTH}(1-34)$-penetratin conjugate from 7.4 to 5 (Figure 1, 
Table 2) can be ascribed to an effect on cell viability accompanied by partly disruption of the Caco-2 monolayer integrity (Figure 2a). Surprisingly, no effect on neither the epithelial integrity (Figure 2a) nor the cellular viability (Figure 2b) was observed as a result of co-administering $\mathrm{PTH}(1-34)$ with penetratin at pH 5.
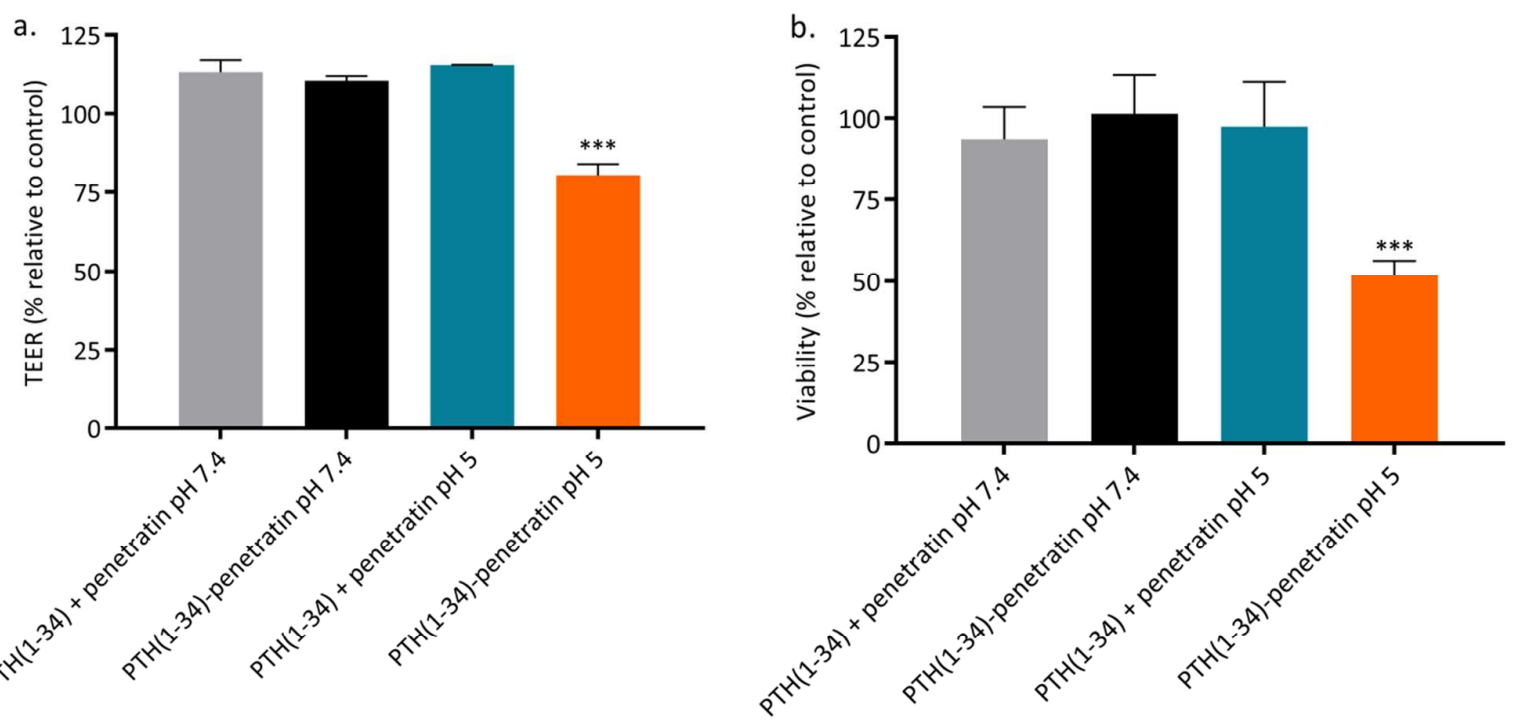

Figure 2. The relative TEER (a) and cellular viability (b) evaluated after apical exposure to $40 \mu \mathrm{M}$ PTH(134)-penetratin conjugate or $40 \mu \mathrm{M} \mathrm{PTH}(1-34)$ co-administered with penetratin (ratio 1:1) at pH 7.4 or pH 5 for $3 \mathrm{~h}$. Results are shown as \% relative to control (10 mM HEPES in HBSS pH 7.4) $\pm \operatorname{SEM}(\mathrm{n}=6, \mathrm{~N}=2)$. Level of significance is $* * *$ : $\mathrm{p}<0.001$ when compared to control ( $\mathrm{pH} 7.4$ buffer).

For assessment of whether the negative effects on the epithelial integrity and cellular viability resulting from incubation with the PTH(1-34)-penetratin conjugate at pH 5 (Figure 2) were reversible, a recovery study was carried out by incubating the Caco- 2 cell monolayers with cell culture medium and $5 \% \mathrm{CO}_{2}$ at $37^{\circ} \mathrm{C}$ for $24 \mathrm{~h}$ prior to evaluation of the TEER (Figure SI 1a) and the cellular viability (Figure SI 1b). After a 24 h recovery period, neither the TEER of the monolayers nor the viability of the cells previously incubated with the $\mathrm{PTH}(1-34)$-penetratin conjugate at $\mathrm{pH} 7.4$ or $\mathrm{PTH}(1-34)$ co-administered with penetratin at $\mathrm{pH} 5$ and 7.4 was lower than that of the buffer-treated controls. However, the TEER of the monolayers, previously incubated with the PTH(1-34)-penetratin conjugate at $\mathrm{pH} 5$, was $50 \%$ higher when compared to the buffer-treated monolayers (Figure SI 1a), and the level of cellular viability only reached $75 \%$ when compared to the buffer-treated control cells (Figure SI 1b). Thus, complete recovery of the monolayer integrity was observed, but the viability of the PTH(1-34)-penetratin treated cells was still compromised when compared to the control cells.

\section{Real-time cellular viability kinetics differ according to $\mathrm{pH}$ and administration approach}

The viability of proliferating Caco-2 cells incubated with $\mathrm{PTH}(1-34)$ conjugated to penetratin or coadministered with penetratin at $\mathrm{pH} 5$ or 7.4 was monitored in real-time over $5 \mathrm{~h}$ using the RealTime-Glo 
assay; a luminescent-based assay measuring the reducing potential of the cells and thus, their viability (Figure 3). As observed in Figure 3a, the kinetics of the cellular viability resulting from incubation with PTH(1-34) co-administered with penetratin or conjugated to penetratin differed both according to $\mathrm{pH}$ and administration approach. Comparing the cellular viability resulting from incubation with PTH(1-34) conjugated to penetratin or $\mathrm{PTH}(1-34)$ co-administered with penetratin at $\mathrm{pH} 7.4$, the kinetics of the cell viability did not differ until the $3 \mathrm{~h}$ time-point. Hereafter, the viability of the cells incubated with the PTH(134)-penetratin conjugate began to decrease. On the other hand, the viability of the cells incubated with PTH(1-34) co-administered with penetratin did not decrease before reaching the $4 \mathrm{~h}$ time-point. At $\mathrm{pH} 5$, differences in the cellular viability kinetics also differed according to whether the cells were incubated with the PTH(1-34)-penetratin conjugate or PTH(1-34) co-administered with penetratin. The cellular viability decreased after approximately $45 \mathrm{~min}$ regardless of whether the cells were incubated with the conjugate or the co-administered PTH(1-34) and penetratin. However, the overall viability of the cells incubated with the $\mathrm{PTH}(1-34)$-penetratin conjugate at $\mathrm{pH} 5$ was significantly lower than for any of the remaining test samples, as also reflected in the calculated area under the curve (AUC) as illustrated in Figure 3b.
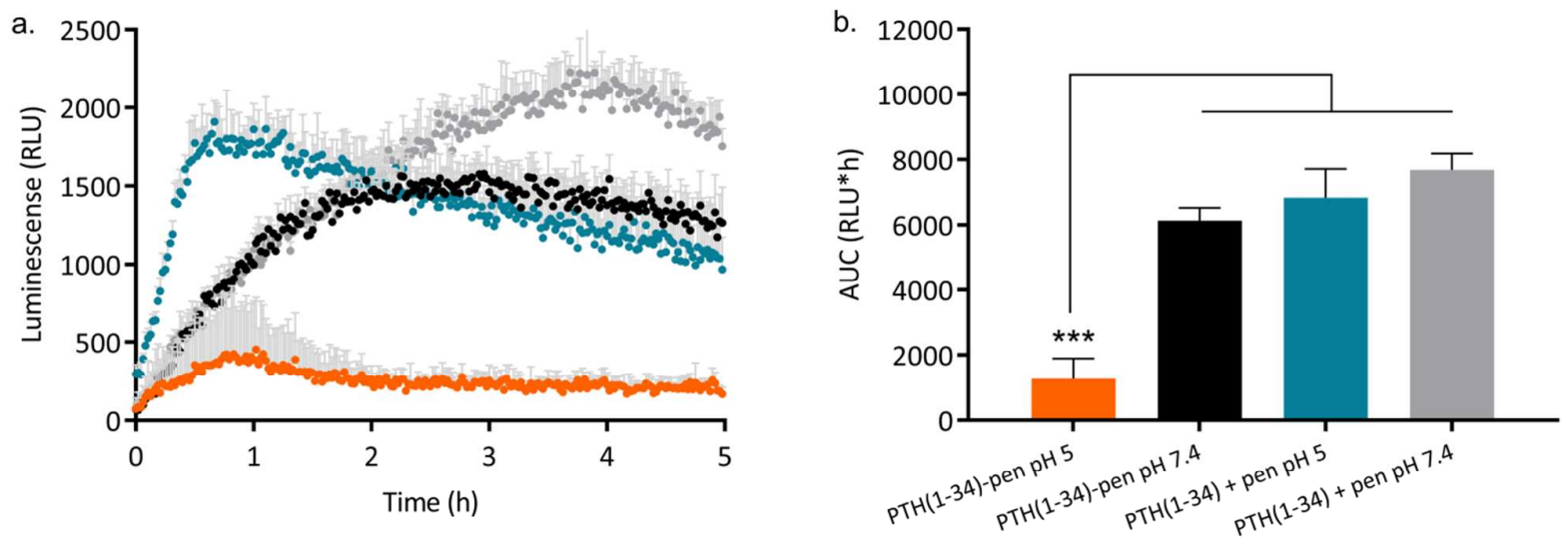

Figure 3. Real time viability of proliferating Caco-2 cells incubated with $40 \mu \mathrm{M} \mathrm{PTH(1-34)-penetratin} \mathrm{or} 40$ $\mu \mathrm{M}$ of PTH(1-34) co-administered with penetratin. Orange: PTH(1-34)-penetratin $\mathrm{pH}$ 5, black: PTH(1-34)penetratin $\mathrm{pH}$ 7.4, blue: $\mathrm{PTH}(1-34)+$ penetratin $\mathrm{pH}$ 5, grey: $\mathrm{PTH}(1-34)+$ penetratin $\mathrm{pH}$ 7.4. Data are presented as luminescent signal over 5 h. (a) or AUC (b) $\pm \operatorname{SEM}(n=6, N=2)$. Level of significance is ***: $\mathrm{p}<0.001$.

Trypan Blue compromised cell staining is pronounced following incubation with the PTH(1-34)penetratin conjugate at $\mathrm{pH} 5$

Proliferating Caco-2 cells incubated with the PTH(1-34)-penetratin conjugate or PTH(1-34) co-administered with penetratin at $\mathrm{pH} 5$ or 7.4 were visually inspected following removal of the test samples and incubation with Trypan Blue (a vital stain taken up only by live cells) (Figure 4). Already after 15 min incubation with the $\mathrm{PTH}(1-34)$-penetratin conjugate at $\mathrm{pH}$, a high number of the cells stained positive with Trypan Blue 
when compared to the cells incubated with the PTH(1-34)-penetratin conjugate at pH 7.4 or PTH(1-34) coadministered with penetratin at $\mathrm{pH} 5$ or 7.4. An observation supporting the other viability studies (Figure 2, 3). Simply lowering the $\mathrm{pH}$ from 7.4 to 5 slightly affected the staining of proliferating Caco-2 cells with Trypan Blue; a tendency also observed from using the RealTime-Glo viability assay following incubation with the pH 5 and 7.4 buffers (Figure SI 2). However, when assessed using the MTS/PMS assay, the viability of the well-differentiated Caco-2 cells was not affected by lowering of the $\mathrm{pH}$ of the sample (Figure 2b) or buffer from 7.4 to 5 (Figure SI 1b).

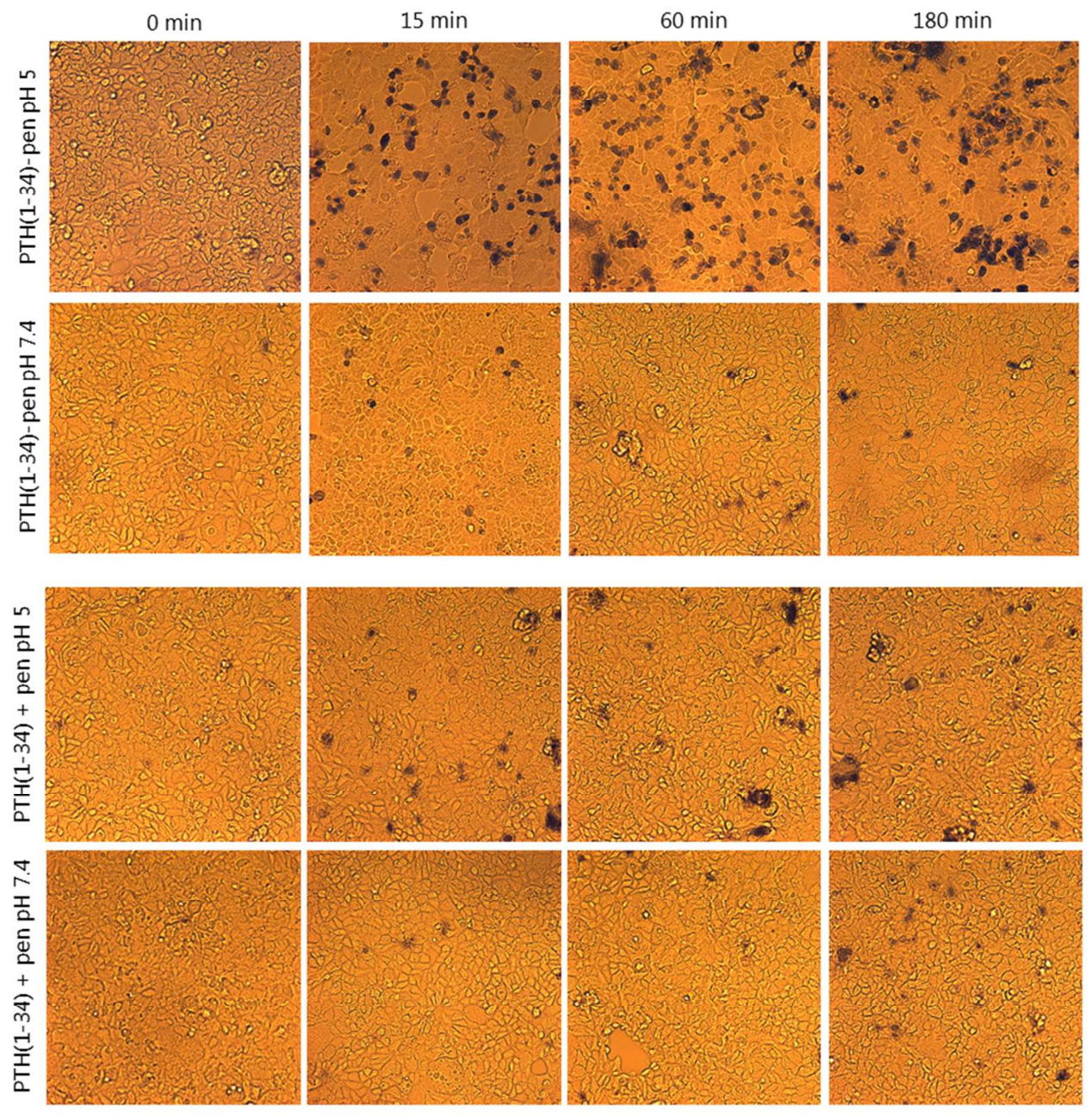

Figure 4. Representative bright field microscopy images from Trypan Blue assay on proliferating Caco-2 cells incubated with $40 \mu \mathrm{M}$ PTH(1-34)-penetratin conjugates or $40 \mu \mathrm{M}$ PTH(1-34) co-administered with penetratin at $\mathrm{pH} 5$ or 7.4 at time points $0,15,60$, and $180 \mathrm{~min}$.

Cells undergo changes in their surface adherence following exposure to the PTH(1-34)-penetratin conjugate at $\mathrm{pH} 5$ 
Measuring changes in impedance during incubation with various samples were achieved using the xCELLigence system, which allows label-free measurements in real-time, thus, eliminating potential adverse effects caused by a label or e.g. additional substrates necessary for a read-out. This approach was implemented in order to explore whether the cellular effects observed earlier with respect to lowering of TEER (Figure 2a) and the cellular viability (Figure 2b, 3, 4) were associated with morphological changes, since changes in impedance can be correlated to changes in adherence of the cells and thus, changes in morphology. A dimensionless value defined as cell index (CI), derived from changes in impedance originating from changes in the cellular coverage of the electrodes, which were incorporated in the bottom of each cell culture well (E-plate), was used to compare the changes in impedance between different treatments. In the present study, the CI of proliferating Caco-2 cells was monitored during a $26.5 \mathrm{~h}$ proliferation period followed by a $2 \mathrm{~h}$ sample incubation period and finally, a recovery period in cell culture medium for approximately $26 \mathrm{~h}$ (Figure 5a). Washing steps were included between each incubation period in order to ensure complete removal of cell medium and sample, respectively. The effect on the CI of the washing step before sample application is observed in Figure $5 \mathrm{~b}$ between the first two time-points.
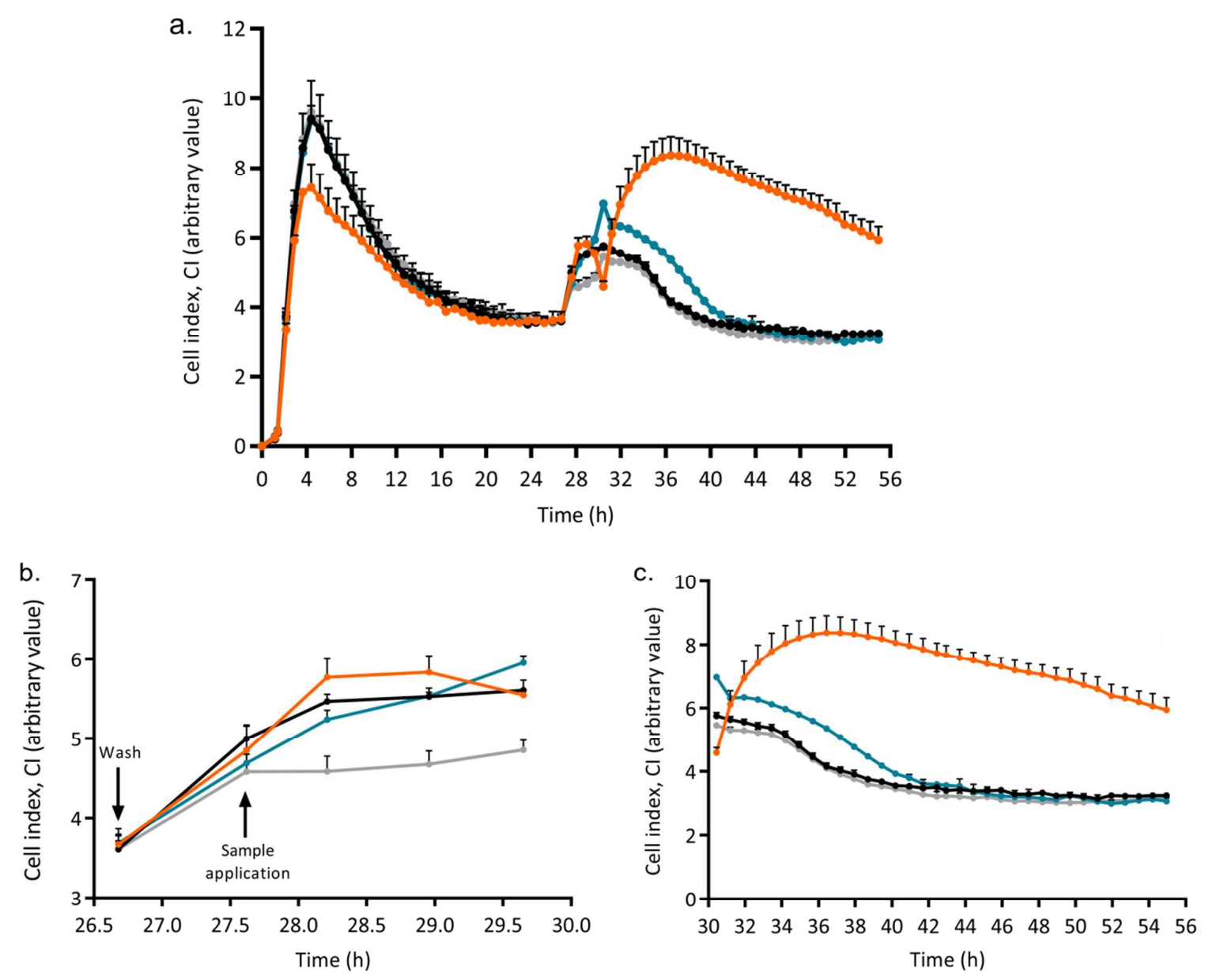
Figure 5. Monitoring morphological changes of Caco-2 cells during a $24 \mathrm{~h}$ proliferation period (a), $2 \mathrm{~h}$ sample incubation $(a, b)$, and a recovery period $(a, c)$ using the xCELLigence system. Samples: $40 \mu \mathrm{M}$ PTH(1-34)-penetratin conjugates or $40 \mu \mathrm{M}$ PTH(1-34) co-administered with penetratin were applied. Orange: PTH(1-34)-penetratin pH 5, black: $\mathrm{PTH}(1-34)$-penetratin $\mathrm{pH}$ 7.4, blue: $\mathrm{PTH}(1-34)+$ penetratin $\mathrm{pH}$ 5, grey: $\mathrm{PTH}(1-34)+$ penetratin $\mathrm{pH}$ 7.4. Data are presented as the average of cell index over $55 \mathrm{~h} \pm \mathrm{SD}(\mathrm{n}=$ $3)$.

After a $20 \mathrm{~h}$ proliferation period, the cells had reached a plateau (Figure 5a), and after approximately $27.5 \mathrm{~h}$ the cell culturing medium was replaced with the samples (Figure $5 b$ ). During sample incubation, an increase in CI was mostly observed for the cells incubated with the PTH(1-34)-conjugate at pH 5 and PTH(1-34) coadministered with penetratin at $\mathrm{pH} 5$, whereas almost no increase in CI was observed for cells incubated with the $\mathrm{PTH}(1-34)$-penetratin conjugate at $\mathrm{pH} 7.4$ or $\mathrm{PTH}(1-34)$ co-administered with penetratin at $\mathrm{pH}$ 7.4.

Nevertheless, the effect on the cell adherence was most pronounced during the recovery period following incubation with the PTH(1-34)-penetratin conjugate at $\mathrm{pH} 5$ (Figure 5c). A slight increase in CI was, however, observed as a result of incubation with $\mathrm{PTH}(1-34)$ co-administered with penetratin at $\mathrm{pH} 5$, when compared to incubation with the $\mathrm{PTH}(1-34)$-penetratin conjugate or $\mathrm{PTH}(1-34)$ co-administered with penetratin at 7.4. Surprisingly, dramatic changes in the adhesive properties of Caco-2 cells exposed to

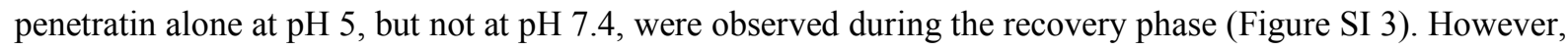
only a slight increase in Trypan Blue uptake was observed during incubation with penetratin alone at $\mathrm{pH} 5$ when compared to $\mathrm{pH} 7.4$ (Figure SI 4). Thus, the changes in adherence resulting from incubation with penetratin alone at $\mathrm{pH} 5$ is not a result of cell death as was the case for incubation with the $\mathrm{PTH}(1-34)-$ penetratin conjugate at $\mathrm{pH} 5$ (Figure 5).

In order to obtain more detailed information about the changes in adherence indirectly observed based on the changes in the CI values using the xCELLigence system (Figure 5), the morphology of the proliferating Caco-2 cells was evaluated by an optical approach using the oCelloscope setup (Figure 6). The oCelloscope is an automated optical detection system enabling real-time image recording collected while scanning through a sample. This optical detection approach was used to evaluate proliferating Caco-2 cells incubated with the PTH(1-34)-penetratin conjugate or PTH(1-34) co-administered with penetratin at pH 5 or 7.4. For each structure caught in focus, a 3D object is generated from which, several morphological parameters can be extracted, such as area and circularity, as depicted in Figure 6. During incubation with PTH(1-34) coadministered with penetratin at both $\mathrm{pH} 5$ and 7.4, an increase in cell area was observed for the first hour, where after a slight decrease in cell area was observed for the rest of the study ( $3 \mathrm{~h}$ in total) (Figure 6a). On the other hand, an almost constant area was detected for cells incubated with the PTH(1-34)-conjugates when compared to cells incubated with PTH(-34) co-administered with penetratin. However, the area of the cells incubated with the PTH(1-34)-penetratin conjugate at $\mathrm{pH} 5$ was much smaller than that of the cells incubated with PTH(1-34) co-administered with penetratin at both $\mathrm{pH} 5$ and 7.4 or the $\mathrm{PTH}(1-34)$-conjugate at $\mathrm{pH}$ 7.4. 
Assessing the cell morphology according to circularity (Figure 6b), the cells incubated with the PTH(1-34)penetratin conjugate at $\mathrm{pH} 5$ were more circular when compared to the cells incubated with the PTH(1-34)penetratin conjugate at $\mathrm{pH} 7.4$ or $\mathrm{PTH}(1-34)$ co-administered with penetratin at both $\mathrm{pH} 5$ and 7.4. The degree of circularity of the cells incubated with the $\mathrm{PTH}(1-34)$-penetratin conjugate at both pH 5 and 7.4 appeared to increase within the first $20 \mathrm{~min}$, where after steady state was reached. On the contrary, an initial increase in circularity of the cells incubated with $\mathrm{PTH}(1-34)$ co-administered with penetratin was not obvious.
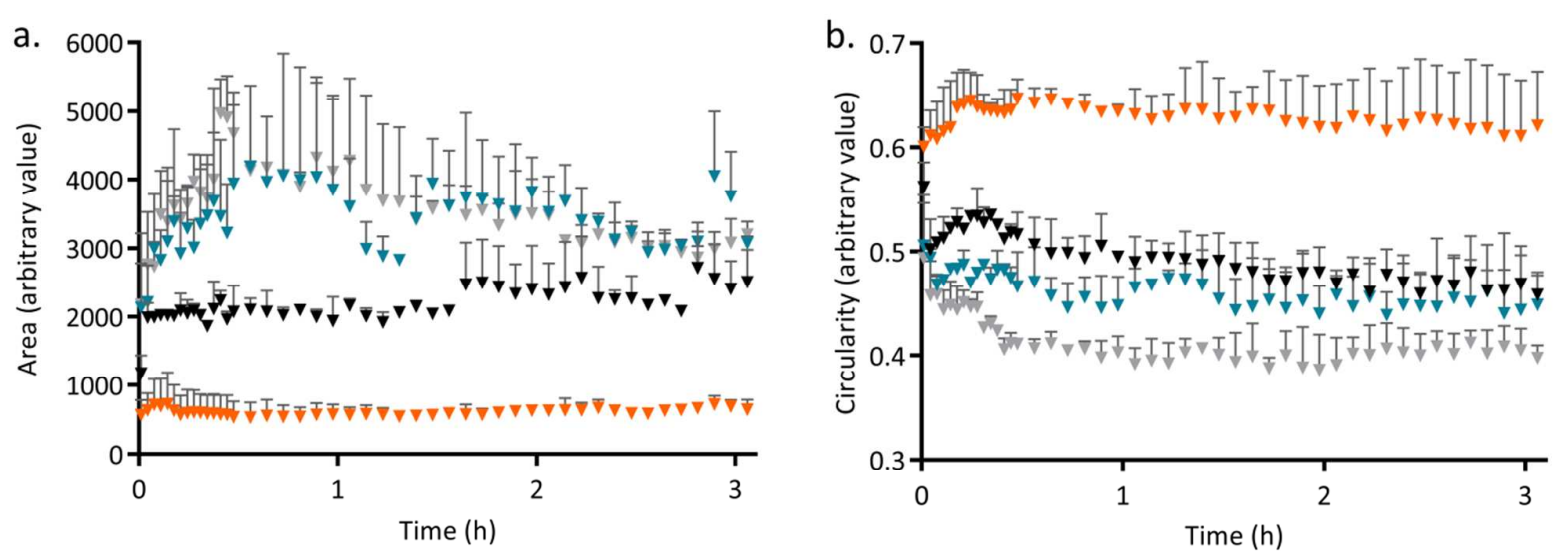

Figure 6. Monitoring of morphological changes of proliferating Caco-2 cells according to area (a) and circularity (b) during a $3 \mathrm{~h}$ sample incubation period (40 $\mu \mathrm{M}$ PTH(1-34)-penetratin conjugates or $40 \mu \mathrm{M}$ PTH(1-34) co-administered with penetratin) using an oCelloscope. Orange: $\mathrm{PTH}(1-34)$-penetratin $\mathrm{pH}$, black: $\mathrm{PTH}(1-34)$-penetratin $\mathrm{pH}$ 7.4, blue: $\mathrm{PTH}(1-34)+$ penetratin $\mathrm{pH}$ 5, grey: $\mathrm{PTH}(1-34)+$ penetratin $\mathrm{pH}$ 7.4. Data are presented as mean $\pm \mathrm{SD}(\mathrm{n}=2)$.

\section{The folding propensity of the PTH(1-34)-conjugates upon membrane contact is not $\mathbf{p H}-\mathrm{dependent}$}

Penetratin adapts an $\alpha$-helical secondary structure in the vicinity of negatively charged lipid membranes, ${ }^{18}$ which is furthermore believed to be of importance for its cell penetrating propensity. ${ }^{19,20}$ Thus, the ability of the PTH(1-34)-penetratin conjugates to fold into a well-defined $\alpha$-helical structure may differ according to $\mathrm{pH}$, and thereby, add to the explanation of the earlier observed $\mathrm{pH}$-dependent effect on the transepithelial PTH(1-34) translocation (Figure 1), cellular viability (Figure 2-5), and cellular morphology (Figure 5, 6). The folding propensity of the $\mathrm{PTH}(1-34)$-penetratin conjugates at $\mathrm{pH} 5$ and 7.4 was assessed in the presence of POPC:POPG liposomes representing a negatively charged lipid membrane using circular dichroism (CD) spectroscopy (Figure 7). However, no difference in folding propensity was observed; both at $\mathrm{pH} 5$ and at $\mathrm{pH}$ 7.4 the PTH(1-34)-penetratin conjugate adapted $\alpha$-helical structures to the same degree with characteristic minima at $208 \mathrm{~nm}$ and $222 \mathrm{~nm}$. 


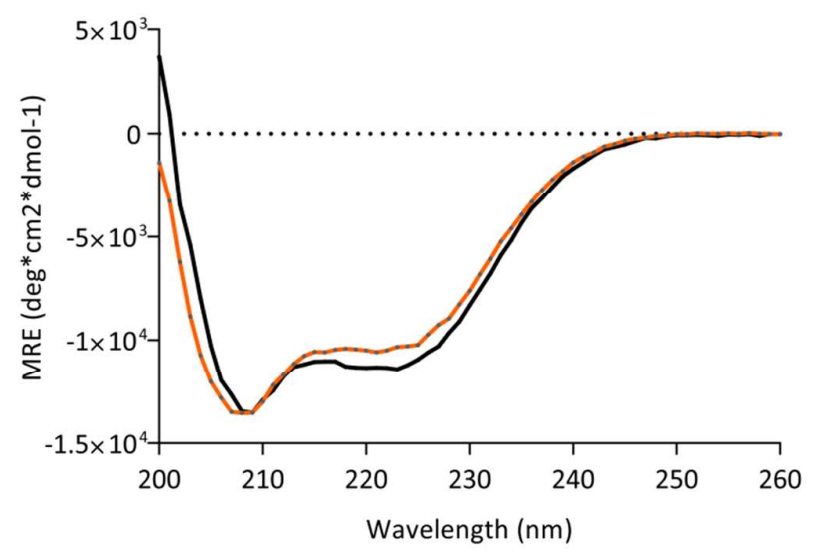

Figure 7. Circular dichroism spectroscopy spectra of $10 \mu \mathrm{M}$ PTH(1-34)-penetratin at $\mathrm{pH} 5$ (orange) or pH 7.4 (black) in the presence of $1 \mathrm{mM}$ POPC:POPG liposomes corresponding to a molar 1:100 peptide to lipid ratio.

\section{The PTH(1-34)-penetratin conjugate is more membrane active at low $\mathrm{pH}$}

Finally, the ability of the PTH(1-34)-penetratin conjugates to induce calcein release from POPC:POPG liposomes was assessed at pH 5 and 7.4 over 20 min (Figure 8). Both at pH 5 and 7.4, an instant calcein release was observed upon applying $0.625 \mu \mathrm{M}$ (Figure 8a), $1.25 \mu \mathrm{M}$ (Figure 8b), or $2.5 \mu \mathrm{M}$ (Figure 8c) of the PTH(1-34)-penetratin conjugate and the release of calcein from the liposomes was concentrationdependent. Moreover, the calcein release was $\mathrm{pH}$-dependent, with the highest percentage of calcein release observed at $\mathrm{pH} 5$ compared to $\mathrm{pH}$ 7.4; thus, suggesting a higher degree of membrane interaction exerted by the $\mathrm{PTH}(1-34)$-penetratin conjugate at $\mathrm{pH} 5$ as compared to $\mathrm{pH} 7.4$.
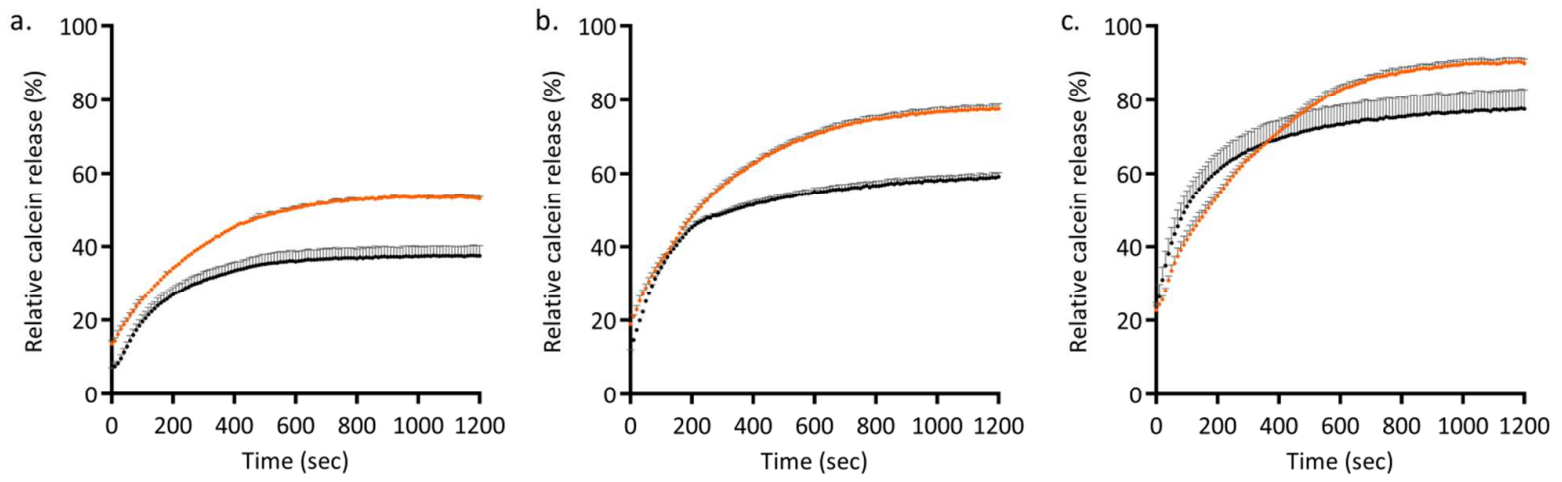

Figure 8. Release of calcein from POPC:POPG liposomes during incubation with $0.625 \mu \mathrm{M}$ (a), $1.25 \mu \mathrm{M}$ (b), or $2.5 \mu \mathrm{M}$ (c) $\mathrm{PTH}(1-34)$-penetratin at $\mathrm{pH} 5$ (orange) or $\mathrm{pH} 7.4$ (black). Data are presented as \% calcein release over 1200 seconds $\pm \operatorname{SD}(n=3)$.

\section{DISCUSSION}


The aim of the present study was to investigate the cellular effect of applying CPPs as permeation enhancers for peptide transport across the intestinal epithelial barrier. Within this context, the influence of $\mathrm{pH}$ as well as administration approach, being co-administration or covalent conjugation, was evaluated using various methods.

A previous study investigating the effect of decreasing the $\mathrm{pH}$ from 7.4 to 5 of insulin co-administered with penetratin in a 1:4 molar ratio resulted in a 6-fold increase of insulin permeation across Caco-2 monolayers, whereas no effect was observed at $\mathrm{pH} 7.4 .^{12}$ At $\mathrm{pH} 7.4$ the propensity of penetratin to enhance $\mathrm{PTH}(1-34)$ permeation across Caco-2 monolayers, when administered in a 1:1 ratio, was dependent on the administration approach applied with co-administration being more effective than conjugation (Figure 1a, Table 2); likely due to the larger molecular size of the conjugate. The outcome of the present study therefore, complements earlier results by concluding that both $\mathrm{pH}$ and the molar therapeutic protein or peptide to penetratin mixing ratio influences the penetratin-mediated transepithelial permeation of the former.

By lowering the $\mathrm{pH}$ from 7.4 to 5, covalent conjugates of penetratin to $\mathrm{PTH}(1-34)$ were as effective in mediating transepithelial $\mathrm{PTH}(1-34)$ permeation as if $\mathrm{PTH}(1-34)$ was co-administered with penetratin (Figure 1b, Table 2). However, at pH 5 the PTH(1-34)-penetratin conjugate negatively affected the cellular viability (Figure $2 a$ ) as well as the epithelial integrity (Figure $2 b$ ). A recovery study demonstrated that after terminating the exposure to the $\mathrm{PTH}(1-34)$-penetratin conjugate at $\mathrm{pH} 5$ and subsequently, incubating the cells with cell medium, the epithelial integrity was restored when assessed after a $24 \mathrm{~h}$ (Figure SI 1a). However, the TEER across the monolayers initially incubated with the PTH(1-34)-penetratin conjugate at $\mathrm{pH} 5$ was $150 \%$ compared to the buffer control when assessed after the $24 \mathrm{~h}$ recovery period. This significant increase in TEER is likely to be a stress-induced effect following incubation with and removal of the seemingly toxic $\mathrm{pH} 5 \mathrm{PTH}(1-34)$-penetratin conjugate, and may not necessarily reflect the integrity of healthy epithelial cells in a monolayer. This is well in line with the fact that the cellular viability was still significantly lower for the cells initially incubated with the PTH(1-34)-penetratin conjugate at pH 5 when compared to the buffer-treated control cells (Figure SI 1b).

It was previously demonstrated that covalent conjugation of an R9 sequence to $\mathrm{PTH}(1-34)$ negatively affected the viability of Caco-2 cells at $\mathrm{pH} 7.4$, whereas co-administration of $\mathrm{PTH}(1-34)$ with the R9 sequence in similar concentrations did not affect the cellular viability. ${ }^{8}$ In that study, it was speculated that the observed toxic effect was a result of the $\mathrm{PTH}(1-34)$ - R9 conjugate being longitudinal amphipathic.

In the present study, exposure to the PTH(1-34)-penetratin conjugate did not give rise to any adverse effects at $\mathrm{pH} 7.4$ in accordance with findings in the previous study. ${ }^{8}$ Conjugation of R9 to PTH(1-34) adds up to a higher density of terminal positive charges when compared to the penetratin sequence. Hence, the degree of longitudinal amphipathicity is greater for the $\mathrm{PTH}(1-34)-\mathrm{R} 9$ conjugate than the $\mathrm{PTH}(1-34)$-penetratin conjugate, which may explain the difference between R9 and penetratin-conjugates. Also, the degree of cytotoxicity has previously been shown to increase as a result of conjugating the CPP Tat to a peptide cargo 
when compared to administration of Tat alone to HeLa or CHO cells; ${ }^{21}$ possibly due to the fact that terminal conjugation of the highly positively charged Tat sequence (pI 12.3) results in longitudinal amphipathicity. However, the negative effect on cellular viability resulting from conjugating a peptide cargo to Tat was in that study not observed as a result of cargo conjugation to penetratin, undecaarginine (R11), or transportan. Thus, whether or not covalent conjugation of a peptide cargo to a CPP will negatively affect the cellular viability is dependent on multiple factors counting the specific CPP and cargo sequences, their concentrations, as well as the cell type and, as demonstrated in the present study, the $\mathrm{pH}$ of the formulation.

In order to elaborate on the negative effect on the cellular viability exerted by the $\mathrm{PTH}(1-34)$-penetratin conjugate at $\mathrm{pH} 5$ following incubation with well-differentiated Caco-2 monolayers (Figure 2b), the viability of proliferating Caco-2 cells were followed using a real-time assay (Figure 3), and compromised cells were visualized using Trypan Blue staining (Figure 4). Both assays supported the outcome of the MTS/PMS assay carried out after the transport study, demonstrating that the $\mathrm{PTH}(1-34)$-penetratin conjugate at $\mathrm{pH} 5$ has a greater negative effect on the cellular viability. In addition, it was clear that the kinetics of the cell viability differed both according to $\mathrm{pH}$ of the sample as well as the administration approach being covalent conjugation or co-administration (Figure 3a). A steeper increase in the luminescent signal was observed during incubation with $\mathrm{PTH}(1-34)$ co-administered with penetratin at $\mathrm{pH} 5$ when compared to $\mathrm{pH}$ 7.4. Due to the fact that the Trypan Blue staining was also more pronounced for the co-administered sample at $\mathrm{pH}$, as opposed to at $\mathrm{pH} 7.4$ (Figure 4), the steep initial increase in the luminescent signal could in principle represent a stress-induced effect by the low $\mathrm{pH}$. However, a similar steep initial increase in the luminescence was observed for the $\mathrm{pH} 7.4$ buffer-treated control cells (Figure SI 2), and therefore, apparently reflect the state of non-compromised cells.

Morphological changes were studied using the xCELLigence system as well as the oCelloscope. In the xCELLigence study (Figure 5), morphological changes were detected for cells during incubation with the PTH(1-34)-penetratin conjugates at $\mathrm{pH} 5$ and PTH(1-34) co-administered with penetratin at $\mathrm{pH}$ 5, whereas almost no effect on the cell morphology was observed during incubation with the $\mathrm{pH} 7.4$ samples (Figure $5 b)$. A similar trend was observed during the post-recovery phase. Here, only a minor increase in CI was observed for cells exposed to $\mathrm{PTH}(1-34)$ co-administered with penetratin at $\mathrm{pH} 5$, whereas a dramatic increase in $\mathrm{CI}$ was obvious for cells exposed to the $\mathrm{PTH}(1-34)$-penetratin conjugate at pH 5 (Figure 5c). Hence, the incubation at $\mathrm{pH} 5$ facilitates cell detachment from the solid support, and the extent to which this occurs, is highly dependent on whether penetratin is covalently conjugated to $\mathrm{PTH}(1-34)$ or co-administered with PTH(1-34). Interestingly, penetratin applied alone at $\mathrm{pH} 5$ had a similar dramatic effect on the cell morphology during the post-recovery phase as observed for the cells subjected to incubation with the PTH(134)-penetratin conjugate at $\mathrm{pH} 5$ (Figure SI 3). However, this post-recovery effect was only observed to a minor extent resulting from incubation with $\mathrm{PTH}(1-34)$ co-administered with penetratin at $\mathrm{pH} 5$. Likely due to the fact that the interaction between penetratin and the cell membrane is hindered by competitive PTH(1- 
34)-membrane interactions and/or e.g. hydrophobic interactions between $\mathrm{PTH}(1-34)$ and penetratin, thus, limiting the availability of penetratin to interact with the cell membrane. Morphological changes of the Caco2 cells during the sample incubation phase were moreover assessed according to cell area and circularity using the oCelloscope (Figure 6). Clear differences in both the cell area and the cell circularity were observed according to administration approach as well as $\mathrm{pH}$. The most pronounced effect on the cell morphology was observed during incubation with the $\mathrm{PTH}(1-34)$-penetratin conjugate at $\mathrm{pH} 5$ resulting in smaller cell areas (Figure 6a) and more circular cells (Figure 6b) as compared to cells incubated with the $\mathrm{PTH}(1-34)$-penetratin conjugate at $\mathrm{pH} 7.4$ or $\mathrm{PTH}(1-34)$ co-administered with penetratin at $\mathrm{pH} 5$ or 7.4 . Thus, the interaction between the proliferating Caco-2 cells with the PTH(1-34)-penetratin conjugate at pH 5 promotes a rounding up of the cells (Figure 6b), thus, making them prone to detachment from the solid support as demonstrated using the xCELLigence system during the post-recovery period after sample replacement with cell medium (Figure 5c).

Finally, in order to explain the pH-dependent penetratin-mediated PTH(1-34) permeation across the Caco-2 monolayer as well as effect on the cell viability only observed following incubation with the PTH(1-34)penetratin conjugate, but not following co-administration of PTH(1-34) with penetratin (Figure 1b, Figure 2), $\mathrm{CD}$ spectroscopy and a calcein release assay was conducted employing the conjugates. Potential pHdependent structural changes of the PTH(1-34)-penetratin conjugate in the vicinity of lipid membranes was assessed using CD spectroscopy (Figure 7), and its ability to disrupt lipid membranes at pH 5 and 7.4 was evaluated by a calcein release assay (Figure 8). A recent study in which different amino acid analogues of the lipidated CPP PepFect 3 were used, demonstrated a direct correlation between the degree of $\alpha$-helical content and the ability to perturb negatively charged lipid membranes for some, but not all CPPs. ${ }^{22}$ This is in line with the outcome of the present study, demonstrating that the PTH(1-34)-penetratin conjugate adapted an $\alpha$ helical structure, and that to the same extent, at both pH 5 and pH 7.4 (Figure 7). However, the ability of the PTH(1-34)-penetratin conjugate to perturb lipid membranes was highly $\mathrm{pH}$-dependent as demonstrated by the calcein release assay (Figure 8). Thus, the $\mathrm{PTH}(1-34)$-penetratin conjugate is likely to be able to penetrate into lipid membranes, and a direct translocation mechanism may therefore account for the penetratin-mediated transepithelial $\mathrm{PTH}(1-34)$ permeation when applied as a conjugate (Figure 1). Furthermore, this is more effective at the lower $\mathrm{pH}$, at which the penetratin sequence bears the highest degree of positive charge. This result supported the outcome of the Caco-2 transport assay demonstrating an increase in $\mathrm{PTH}(1-34)$ permeation, when lowering the $\mathrm{pH}$ of the $\mathrm{PTH}(1-34)$-penetratin conjugate to the $\mathrm{pH}$ at which the conjugate is most membrane active, i.e. being longitudinal amphipathic (Figure 1). On the other hand, the penetratin-mediated transepithelial $\mathrm{PTH}(1-34)$ permeation following co-administration may take place mainly via endocytic uptake following transcytosis due to the lack of the longitudinal amphipathicity. Endocytic uptake has earlier been suggested to be the main mechanism driving the cellular internalization of penetratin and a number of additional $\mathrm{CPPs} .{ }^{23,24}$ However, the conjugation of a cargo peptide to highly 
positively charged CPPs adds longitudinal amphipathicity to the resulting molecule, which then acts on cell membranes in a detergent-like manner. Nevertheless, more focused mechanistic studies must be conducted in order to fully explain the mechanisms in play for the CPP-mediated transepithelial cargo delivery as a result of covalent conjugation or co-administration and variable $\mathrm{pH}$.

\section{CONCLUSIONS}

In the present study the penetratin-mediated PTH(1-34) permeation across Caco-2 monolayers was evaluated at $\mathrm{pH} 7.4$ and 5 as a result of either co-administering $\mathrm{PTH}(1-34)$ with penetratin or with penetratin conjugated to the C-terminal of $\mathrm{PTH}(1-34)$. At $\mathrm{pH}$ 7.4, the co-administration approach was significantly more effective than the conjugation approach. Decreasing the $\mathrm{pH}$ of the $\mathrm{PTH}(1-34)$-penetratin conjugate to pH 5 increased the PTH(1-34) permeation significantly, reaching the same level as when co-administered at $\mathrm{pH}$ 7.4. However, this $\mathrm{pH}-$ mediated increase in $\mathrm{PTH}(1-34)$ permeation was associated with a negative effect on the cell viability as also reflected by a decrease in the integrity of well-differentiated Caco-2 monolayers as well as morphological changes of proliferating Caco-2 cells grown on solid supports. On the contrary, no cytotoxic effect was observed as a result of co-administering $\mathrm{PTH}(1-34)$ with penetratin at $\mathrm{pH}$, demonstrating that the co-administration approach may constitute the safer alternative to the conjugation approach. Finally, membrane interaction studies revealed that the enhanced epithelial permeation of the PTH(1-34)-penetratin conjugate observed at $\mathrm{pH} 5$ was associated with negative effects on the cell viability, but cannot be explained by differences in the ability of the conjugate to adapt a well-defined $\alpha$-helical structure upon membrane interaction. Nevertheless, the PTH(1-34)-penetratin conjugate lead to calcein leakage from lipid vesicles to a greater extent at $\mathrm{pH} 5$ than at $\mathrm{pH} 7.4$ indicating some difference in the membrane interaction at different $\mathrm{pH}$ values.

Thus, from the present study it can be concluded that when applying highly positively charged CPPs as epithelial permeation enhancers for a peptide cargo, the covalent conjugation approach may, in synergy with a change in local $\mathrm{pH}$, compromise the cells in the epithelium when the $\mathrm{pH}$ dictate full protonation of the CPP and thus, ensures longitudinal amphipathicity of the conjugate.

\section{MATERIALS AND METHODS}

\section{Materials}

Coupling reagents and rink amide resin for the synthesis of penetratin were obtained from Fluka (Buchs, Switzerland). Solvents and amino acids for the penetratin synthesis were obtained from Iris Biotech (Merktredwitz, Germany). Primers for the PTH(1-34)-penetratin fusion peptide was designed using VectorNTI software (Life Technologies, Naerum, Denmark) and obtained from GeneArt (Life Technologies, Naerum, Denmark). Forward primer: TACTTCCAATCCTCGGTTAGCGAAATTCAGCTGATGCATAATCTGG. Reverse primer: TATCCACCTTTACTGTTAAAAGTTATGCACATCCTGCAGT- 
TTTTTACGCAG. E. coli Mach1 cells (Life Technologies, Naerum, Denmark) were used for cloning with kanamycin $(50 \mu \mathrm{g} / \mathrm{mL})$ and chloramphenicol $(35 \mu \mathrm{g} / \mathrm{mL})$ (Sigma Aldrich, Buchs, Switzerland). The cells were grown in Terrific Broth (TB) medium (tryptone $12.0 \mathrm{~g} / \mathrm{L}$, yeast extract $24.0 \mathrm{~g} / \mathrm{L}, \mathrm{K}_{2} \mathrm{HPO}_{4} 9.4 \mathrm{~g} / \mathrm{L}$, $\mathrm{KH}_{2} \mathrm{PO}_{4} 2.2 \mathrm{~g} / \mathrm{L}$ ) supplemented with $8 \mathrm{~g} / \mathrm{L}$ glycerol (Sigma Aldrich, Buchs, Switzerland). For inhibition of enzymatic activity during protein purification complete Mini EDTA-free Protease Inhibitor Tablets were used (Roche, Hvidovre, Denmark). All enzymes were purchased from New England Biolab (Ipswich, MA, USA) and synthetic PTH(1-34) was obtained from Bachem (Bubendorf, Switzerland). Dulbecco's Modified Eagle Medium (DMEM) for cell culturing was obtained from Life Technologies (Naerum, Denmark) and Hanks Balanced Salt Solution (HBSS) from Invitrogen (Naerum, Denmark). 3-(4,5-dimethylthiazol-2-yl)-5(3-carboxymethoxyphenyl)-2-(4-sulfophenyl)-2H-tetrazolium (MTS) was purchased from Promega (Madison, WI, USA). Liposomes were prepared using 1-palmitoyl-2-oleoyl-sn-glycero-3-phosphocholine (POPC): 1-palmitoyl-2-oleoyl-sn-glycero-3-phosphoglycerol (POPC:POPG) obtained from Avanti Polar Lipids (Alabaster, AL, USA). All other materials were obtained from Sigma Aldrich (Buchs, Switzerland).

\section{PTH(1-34)-penetratin fusion peptide production and peptide synthesis}

Expression constructs: The PTH(1-34)-penetratin fusion peptide was cloned, expressed and purified as previously described. ${ }^{8}$ Penetratin was synthesized and purified as earlier described. ${ }^{12}$

\section{Cell culture model}

Caco-2 cells were obtained from American Type Cell Cultures (ATCC, Manassas, VA, USA) and maintained as previously described ${ }^{12}$. For the permeability experiments $1.0 \times 10^{5}$ cells were grown on polycarbonate membrane inserts (diameter $12 \mathrm{~mm}$, area $1.13 \mathrm{~cm}^{2}$, pore size $0.4 \mu \mathrm{m}$ ) (Corning Costar, Costar, NY, USA) in a 12-well Transwell plate (Corning Costar, Costar, NY, USA) for 20 days to form a tight epithelium.

For experiments applying proliferating Caco-2 cells in $90 \%$ confluent monolayers, cells were seeded on collagen-coated 96-well plates at a density of $6 \times 10^{4}$ cells/well and cultured for $24 \mathrm{~h}$ in DMEM supplemented with $90 \mathrm{U} / \mathrm{mL}$ penicillin, $90 \mu \mathrm{g} / \mathrm{mL}$ streptomycin, $2 \mathrm{mM}$ L-glutamine, $0.1 \mathrm{mM}$ non-essential amino acids, and $10 \%(\mathrm{v} / \mathrm{v})$ fetal bovine serum (FBS) (Fischer Scientific, Slangerup, Denmark).

For impedance measurements with the xCELLigence system, $6 \times 10^{4}$ Caco- 2 cells suspended in cell culturing medium were seeded in each well of a collagen-coated E-plate (ACEA Biosciences, San Diego, CA, USA) and incubated in the xCELLigence system (at $37^{\circ} \mathrm{C}$ and $5 \% \mathrm{CO}_{2}$ ), and grown for $26.5 \mathrm{~h}$.

\section{In vitro transepithelial permeability}

Test samples containing $40 \mu \mathrm{M}$ PTH(1-34)-penetratin fusion peptide or equimolar concentration of PTH(134) in a physical mixture with penetratin were prepared in HBSS immediately before the experiment. The 
solutions were either supplemented with $10 \mathrm{mM}$ MES and adjusted to $\mathrm{pH} 5$ (mHBSS) or with $10 \mathrm{mM}$ HEPES and adjusted to $\mathrm{pH} 7.4$ (hHBSS). The experiment was performed at $37^{\circ} \mathrm{C}$ and with horizontal shaking as previously described. ${ }^{12}$ The Caco- 2 cell monolayers were washed twice apical and basolateral with $37^{\circ} \mathrm{C}$ hHBSS and equilibrated to room temperature in hHBSS, before the transepithelial electrical resistance (TEER) was measured using an EVOM equipped with an Endohm-12 cup (World Precision Instruments, Sarasota, FL, USA). Only filters with an initial TEER $>200 \Omega * \mathrm{~cm}^{2}$ were used for transports experiments. Upon re-equilibration to $37^{\circ} \mathrm{C}, 500 \mu \mathrm{L}$ test sample was added to the apical side of the Caco-2 cell monolayer, and $100 \mu \mathrm{L}$ samples were withdrawn from the basolateral side at defined time points. Samples containing PTH(1-34) were withdrawn every 60 min for $3 \mathrm{~h}$ with following quantification using a PTH(1-34) EIA kit (Bachem, Bubendorf, Switzerland) and absorbance measurement at $450 \mathrm{~nm}$ using a FLUOstar OPTIMA plate reader (BMG Labtech, Offenburg, Germany). $100 \mu \mathrm{L}$ samples were withdrawn every 30 min over $3 \mathrm{~h}$ and subsequently, analyzed using a scintillation counter (Packard Tri-Carb 2100 TR, Canberra, Dreieich, Germany) after mixing with $2 \mathrm{~mL}$ Ultima Gold (Perkin Elmer, Waltham, MA, USA). After the permeation experiment, the epithelia were washed twice on the apical and basolateral sides with $37^{\circ} \mathrm{C}$ hHBSS and equilibrated to room temperature before the TEER was assessed in order to evaluate the effect on the monolayer integrity following sample incubation. All experiments were performed in triplicate each on 2-3 consecutive passages between number 5 and 20 .

The apparent permeability coefficient $\left(\mathrm{P}_{\text {app }}\right)$ was calculated by using the equation:

$\mathrm{P}_{\text {app }}(\mathrm{cm} / \mathrm{s})=\mathrm{dQ} / \mathrm{dt} \times 1 /\left(\mathrm{A} \times \mathrm{C}_{0}\right)$

where $\mathrm{dQ} / \mathrm{dt}$ is the steady state flux, $\mathrm{A}\left(1.13 \mathrm{~cm}^{2}\right)$ is the area of the Caco-2 monolayer and $\mathrm{C}_{0}$ is the initial donor concentration applied to the apical side of the cell monolayer.

\section{Cellular viability and cytotoxicity}

The MTS/PMS assay previously described by Cory et al ${ }^{25}$ was used to determine the cellular viability of the Caco-2 cells in the monolayer after the permeability study. Briefly, after the experiment and TEER measurement, the monolayers were washed twice on the apical and basolateral sides with $37^{\circ} \mathrm{C} \mathrm{hHBSS}$, and $0.32 \mathrm{~mL} \mathrm{MTS} / \mathrm{PMS}$ solution (240 $\mu \mathrm{g} / \mathrm{mL}$ MTS, $2.4 \mu \mathrm{g} / \mathrm{mL}$ PMS) was added to the apical side of the monolayer and incubated for $1.5 \mathrm{~h}$ protected from light under horizontal shaking $\left(50 \mathrm{rpm}, 37^{\circ} \mathrm{C}\right) .2 \times 100 \mu \mathrm{L}$ samples were withdrawn from the apical side of each filter and the absorbance of the formed formazan product was measured at $492 \mathrm{~nm}$ using a POLARstar OPTIMA plate reader (BMG Labtech, Offenburg, Germany). The relative cellular viability was determined by:

Relative viability $(\%)=\left(\mathrm{A}_{\text {sample }}-\mathrm{A}_{\mathrm{SDS}}\right) /\left(\mathrm{A}_{\text {buffer }}-\mathrm{A}_{\mathrm{SDS}}\right) \times 100 \%$

where $A_{\text {sample }}$ is the absorbance of the withdrawn samples, $A_{S D S}$ is the absorbance of cell monolayers incubated with $(0.2 \%(\mathrm{w} / \mathrm{v})$ sodium dodecyl sulphate) corresponding to $0 \%$ cell viability (positive control), 
and $\mathrm{A}_{\text {buffer }}$ is the absorbance of the negative control; i.e. cells incubated with buffer corresponding to $100 \%$ cell viability.

The viability of 96-well grown Caco-2 cells during exposure to test samples was assessed in real-time using the RealTime-Glo MT Cell Viability Assay (Promega, Madison, WI, USA) according to the manufacturer's directions. Briefly, the cells were washed twice in $0.2 \mathrm{~mL} 37^{\circ} \mathrm{C}$ hHBSS prior to incubation with $100 \mu \mathrm{L}$ reagent (MT Viability Substrate and NanoLuc Enzyme 1:1) for $5 \mathrm{~min}$ at $37^{\circ} \mathrm{C}$. Double concentrated test samples, in equal volumes as the reagent, were added to the cells and luminescence was measured every 30 sec at $37^{\circ} \mathrm{C}$ using a FLUOstar OPTIMA plate reader (BMG Labtech, Offenburg, Germany). Cells incubated with buffer served as negative control.

For visualizing membrane-compromised cells, Trypan Blue was used. Caco-2 cells cultured in 96-wells were washed twice in hHBSS prior to incubation with test samples containing $40 \mu \mathrm{M}$ PTH(1-34)-penetratin fusion peptide or an equimolar concentration of $\mathrm{PTH}(1-34)$ in a physical mixture with penetratin. The experiment was carried out at $37^{\circ} \mathrm{C}$ with horizontal shaking (50 rpm). Following sample incubation for $15 \mathrm{~min}, 60 \mathrm{~min}$, $120 \mathrm{~min}$, and $180 \mathrm{~min}$, the cells were washed twice in $37^{\circ} \mathrm{C}$ hHBSS followed by incubation with $0.2 \%(\mathrm{w} / \mathrm{v})$ Trypan Blue in hHBSS for $15 \mathrm{~min}\left(50 \mathrm{rpm}, 37^{\circ} \mathrm{C}\right)$. The Trypan Blue solution was removed and the cells were washed twice in $37^{\circ} \mathrm{C}$ hHBSS, and visualized by using a Nikon Eclipse Ti inverted microscope (Nikon, Tokyo, Japan) equipped with a CFI S Plan Fluor 20X objective and a 12/100 W halogen lamp (Nikon instruments, Amsterdam, The Netherlands). Images were recorded with an Lt425C Lumenera camera and processed using LuCam image software (both Lumenera, Ottawa, ON, Canada).

\section{Cellular morphology and adherence real-time experiments}

The morphology of Caco-2 cells cultured for $24 \mathrm{~h}$ were followed optically using the oCelloscope system (Philips BioCell A/S, Alleroed, Denmark) and their adherence/intercellular interactions electrochemically by measuring changes in impedance employing the xCELLigence setup (ACEA Biosciences, San Diego, CA, USA).

For the studies with the oCelloscope, Caco-2 cells cultured for $24 \mathrm{~h}$ in a 96 well plate were washed twice with $37^{\circ} \mathrm{C}$ hHBSS. The focus was manually adjusted for each well and the illumination level was set to 186 and the illumination time to $2 \mathrm{~ms}$. The experiment was performed at $37^{\circ} \mathrm{C}$ and $5 \% \mathrm{CO}_{2}$ with scans of the wells obtained every $2 \mathrm{~min}$ within the first $30 \mathrm{~min}$ and every $5 \mathrm{~min}$ the following $150 \mathrm{~min}$. At each time point 15 images were collected of each well creating a $1470 \mu \mathrm{m}$ length of the scan covering $2.5 \mathrm{~mm}^{2}$. Images were processed using the UniExplorer software version 6.0 and the segmentation feature was used to calculate cell area and circularity.

For impedance measurements with the xCELLigence system, the cells were washed twice in $37^{\circ} \mathrm{C}$ hHBSS $\mathrm{pH} 7.4,100 \mu \mathrm{L}$ test sample per well was added and the incubation continued under the same conditions for 2 h. Hereafter, the samples were discarded, the cells were washed twice in $37^{\circ} \mathrm{C}$ hHBSS before continuous 
incubation in cell medium for an additional approximately $26 \mathrm{~h}$. The experiment was performed in triplicate and the cell index $(\mathrm{CI})$ was recorded over $55 \mathrm{~h}$ in total.

$\mathrm{CI}=($ Impedance at time point $\mathrm{n}-$ impedance in the absence of cells)/nominal impedance value (Eq. 3)

\section{Liposome preparation}

CD spectroscopy, unilamellar anionic POPC:POPG liposomes in a molar 80:20 ratio were produced by the thin film method as previously described by Foged et al. ${ }^{26}$ Briefly, dry lipid films were formed for lipid solutions in round bottom flasks by applying vacuum over night before hydration in HEPES buffer (10 mM HEPES, $150 \mathrm{mM} \mathrm{KCl}_{1} 1 \mathrm{mM} \mathrm{NaN}_{3}, 0.04 \mathrm{mM}_{\text {EDTA, }} 0.03 \mathrm{mM} \mathrm{CaCl}_{2}$, $\mathrm{pH}$ 7.4) to a final lipid concentration of $20 \mathrm{mM}$ with agitation every $10 \mathrm{~min}$ for $1 \mathrm{~h}$ before annealing for $1 \mathrm{~h}$. The obtained liposomes were extruded (Lipex Biomembranes Extruder, Vancouver, BC, Canada) 10 times through $100 \mathrm{~nm}$ polycarbonate filters (Whatman, Herlev, Denmark) and vesicle sizes verified by dynamic light scattering at $25^{\circ} \mathrm{C}$ using a Zetasizer Nano ZS (Malvern Optics Instruments, Worcestershire, UK) equipped with a $633 \mathrm{~nm}$ laser. The phospholipid content was assessed by using a Phospholipid B enzymatic kit (mti Diagnostics, Idstein, Germany) according to the manufacturer's recommendations.

For the calcein release assay, lipid films were prepared as described above, but hydrated in HEPES buffer containing $70 \mathrm{mM}$ calcein before agitation and annealing. Excess calcein, not entrapped in the liposomes, were removed by passing the liposome suspension through four Sephadex G-50 columns (GE Healthcare, Broendby, Denmark) before the vesicle sizes were verified by DLS.

\section{Peptide folding propensity}

CD spectra were measured in the range of $180-260 \mathrm{~nm}$ on a JASCO CD spectrophotometer (Easton, MD, USA) using a $1 \mathrm{~mm}$ cuvette (Helma Analytics, Müllheim, Germany). Measurements were performed at $20^{\circ} \mathrm{C}$ with peptides dissolved in $2.5 \mathrm{mM}$ MES pH 5 or $2.5 \mathrm{mM}$ HEPES pH 7.4 in the presence of POPC:POPG (80:20 molar ratio) liposomes with a fixed peptide-to-lipid ratio of 1:50. All spectra represent an average of 10 scans, which have been background-corrected and transformed into mean residue ellipticity (MRE) as calculated by:

$\operatorname{MRE}\left(\operatorname{deg} \times \mathrm{cm}^{2} \times \mathrm{dmol}^{-1}\right)=(\operatorname{MRW} \times \lambda) /(10 \times \mathrm{d} \times \mathrm{C})$

where MRW is the mean residue molar weight, $\lambda$ is the ellipticity in mdeg, $d$ is the path length in $\mathrm{cm}$, and $\mathrm{C}$ is the molar concentration.

\section{Membrane disruption}

$180 \mu \mathrm{L}$ volumes of test samples in concentrations ranging $0.625-5 \mu \mathrm{M}$ were added to the wells of black clear-bottom 96-well plates (Corning Costar, Costar, NY, USA) and $20 \mu \mathrm{L}$ of calcein-loaded liposome suspension was added to each well (reaching a final lipid concentration of $25 \mu \mathrm{M}$ ) immediately before 
starting the measurement of the fluorescence intensity. The fluorescence was measured at $37^{\circ} \mathrm{C}$ on a POLARstar Optima plate reader (BMG Labtech, Offenburg, Germany) every $10 \mathrm{sec}$ for $1 \mathrm{~h}$ with excitation and emission set at $485 \mathrm{~nm}$ and $520 \mathrm{~nm}$, respectively. After the last measurement, $10 \%$ (w/v) Triton X-100 was added as control for $100 \%$ calcein release.

Percent encapsulated calcein was calculated for liposomes without added test samples by:

$\%$ encapsulated calcein $=(($ FaTX - FbTX $) / F a T X) * 100 \%$

where FaTX and FbTX is fluorescence after and before the addition of Triton X-100, respectively.

Percent calcein release was calculated as:

$\%$ calcein release $=100-(\%$ encapsulated at $\mathrm{x} \min / \%$ encapsulated at $0 \mathrm{~min})$

(Eq. 6)

\section{Data and statistical analysis}

Microsoft Office Excel 2010 and GraphPad Prism version 7 (GraphPad Software, San Diego, CA, USA) were employed for data processing. Statistical analysis was done in GraphPad Prism version 6 using one way analysis of variance (ANOVA) and two-way ANOVA. Data are presented as mean \pm standard error of mean (SEM) or mean \pm standard deviation (SD) with $\mathrm{n}$ representing the total number of replicates, and $\mathrm{N}$ representing the number of passages.

\section{ASSOCIATED CONTENT}

\section{Supporting information}

TEER and viability of Caco-2 recovery study following sample and buffer incubation (Figure SI 1), real-time viability of Caco-2 cells incubated with pH 5 and 7.4 buffer controls obtained by the RealTime-Glo assay (Figure SI 2), morphological changes of Caco-2 cells after incubation with penetratin at $\mathrm{pH} 5$ and 7.4 assessed using the xCELLigence system (Figure SI 3), Tryphan Blue uptake in Caco-2 cells during incubation with penetratin at pH 5 and 7.4 (Figure S4).

\section{ACKNOWLEDGEMENTS}

Maria Læssøe Pedersen (Senior Technician) and Thara Hussein (Technician) (Department of Pharmacy, University of Copenhagen) are acknowledged for the cell culturing work. This project was financially supported by the Drug Research Academy (University of Copenhagen), The Novo Nordisk Foundation Center for Protein Research, The Danish Agency for Science, Technology and Innovation, DanCARD (grant no. 06-097075). Furthermore, the research leading to these results received support from the Innovative Medicines Initiative Joint Undertaking under grant agreement $n^{\circ} 115363$ resources, which are composed of financial contribution from the European Union's Seventh Framework Programme (FP7/2007-2013) and EFPIA companies in kind contribution. Moreover, The Danish Research Council for Technology and Production (FTP) (project DFF-4004-00120B) is acknowledged for financial support (LHN). Finally, the 
Danish National Research Foundation (project DNRF122), the Villum Foundation's Center (grant no. 9301) for Intelligent Drug Delivery and Sensing Using Microcontainers and Nanomechanics (IDUN), and the European Research Council under FP7/2007-2013 (grant no. 320535-HERMES) are acknowledged.

\title{
AUTHOR INFORMATION
}

\section{Corresponding author}

E-mail: hanne.morck@sund.ku.dk. Tel.: +4535336063

\section{Notes}

The authors declare no conflicts of interest

\author{
ABBREVIATIONS \\ CPP: Cell-penetrating peptide \\ CD: Circular dichroism \\ CI: Cell index \\ MRE: Mean residue ellipticity \\ $\mathrm{P}_{\text {app: }}$ : Apparent permeability coefficient \\ PTH: Parathyroid hormone \\ TEER: Transepithelial electrical resistance
}

\section{REFERENCES}

1. Kristensen M, Nielsen HM (2016). Cell-penetrating peptides as tools to enhance non-injectable delivery of biopharmaceuticals. Tissue Barriers. 9, e11788378.

2. Khafagy E-S, Morishita M (2012). Oral biodrug delivery using cell-penetrating peptide. Adv. Drug Deliv. Rev. 64, 531-539.

3. Morishita M, Kamei N, Ehara J, Isowa K, Takayama K (2007). A novel approach using functional peptides for efficient intestinal absorption of insulin. J. Control. Release. 118,177-184.

4. Kamei N, Morishita M, Eda Y, Ida N, Nishio R, Takayama K (2008). Usefulness of cell-penetrating peptides to improve intestinal insulin absorption. J Control. Release. 132, 1-25.

5. Patel L, Wang J, Kim K (2009). Conjugation with cationic cell-penetrating peptide increases pulmonary absorption of insulin. Mol. Pharm. 6, 492-503.

6. Kristensen M, Nielsen $\mathrm{HM}(2015)$. Cell-penetrating peptides as carriers for oral delivery of biopharmaceuticals. Basic Clin. Pharmacol. Toxicol. 118, 99-106.

7. Derossi D, Joliot AH, Chassaing G, Prochiantz A. The third helix of the Antennapedia homeodomain translocates through biological membranes (1994). J. Biol. Chem. 269, 10444-10450. 
8. Kristensen M, de Groot AM, Berthelsen J, Franzyk H, Sijts A, Nielsen HM (2015). Conjugation of cell-penetrating peptides to parathyroid hormone affects its structure, potency, and transepithelial permeation. Bioconjug. Chem. 26, 477-488.

9. Kamei N, Morishita M, Takayama K (2009). Importance of intermolecular interaction on the improvement of intestinal therapeutic peptide/protein absorption using cell-penetrating peptides. $J$. Control. Release. 136, 179-186.

10. Kamei N, Kikuchi S, Takeda-morishita M, Terasawa Y, Yasuda A, Yamamoto S, Ida N, Nishio R, Takayama K (2013). Determination of the optimal cell-penetrating peptide sequence for intestinal insulin delivery based on molecular orbital analysis with self-organizing maps. J. Pharm. Sci.102, 469-479.

11. Kamei N, Aoyama Y, Khafagy E-S, Henmi M, Takeda-Morishita M (2015). Effect of different intestinal conditions on the intermolecular interaction between insulin and cell-penetrating peptide penetratin and on its contribution to stimulation of permeation through intestinal epithelium. Eur. $J$. Pharm. Biopharm. 94, 42-51.

12. Kristensen M, Franzyk H, Klausen MT, Iversen A, Søborg Bahnsen J, Bjerring Skyggebjerg R, Foderà V, Nielsen HM (2015). Penetratin-mediated transepithelial insulin permeation: Importance of cationic residues and $\mathrm{pH}$ for complexation and permeation. AAPS J. 17, 1200-1209.

13. Henriksen K, Andersen JR, Riis BJ, Mehta N, Tavakkol R, Alexandersen P, Byrjalsen I, Valter I, Nedergaard BS, Teglbjærg CS et al. (2013). Evaluation of the efficacy, safety and pharmacokinetic profile of oral recombinant human parathyroid hormone $[\mathrm{rPTH}(1-31) \mathrm{NH} 2]$ in postmenopausal women with osteoporosis. Bone. 53, 160-166.

14. Crotts G, Isaac G-S, Sheth A (2008). Oral peptide pharmaceutical dosage form and method of production. US Pat. 7,316-819.

15. Binkley N, Bolognese M, Sidorowicz-Bialynicka A, Vally T, Trout R, Miller C, Buben CE, Gilligan JP, Krause DS (2012). A phase 3 trial of the efficacy and safety of oral recombinant calcitonin: The Oral Calcitonin in Postmenopausal Osteoporosis (ORACAL) trial. J. Bone Miner. Res. 27, 18211829.

16. Smart AL, Gaisford S, Basit AW (2014). Oral peptide and protein delivery: intestinal obstacles and commercial prospects. Expert Opin. Drug Deliv. 11, 1323-1335.

17. Choonara BF, Choonara YE, Kumar P, Bijukumar D, du Toit LC, Pillay V (2014). A review of advanced oral drug delivery technologies facilitating the protection and absorption of protein and peptide molecules. Biotechnol. Adv. 32, 1269-1282.

18. Bahnsen JS, Franzyk H, Sandberg-Schaal A, Nielsen HM (2013). Antimicrobial and cell-penetrating 
properties of penetratin analogs: effect of sequence and secondary structure. Biochim. Biophys. Acta. $1828,223-232$.

19. Christiaens B, Grooten J, Reusens M, Joliot A, Goethals M, Vandekerckhove J, Prochiantz A, Rosseneu M (2004). Membrane interaction and cellular internalization of penetratin peptides. Eur. $J$. Biochem. 271, 1187-1197.

20. Rydberg HA, Carlsson N, Nordén B (2012). Membrane interaction and secondary structure of de novo designed arginine and tryptophan peptides with dual function. Biochem. Biophys. Res. Commun. $427,261-265$.

21. Jones SW, Christison R, Bundell K, Voyce CJ, Brockbank SMV, Newham P, Lindsay MA (2005). Characterisation of cell-penetrating peptide-mediated peptide delivery. Br. J. Pharmacol. 145, 10931102.

22. Regberg J, Vasconcelos L, Madani F, Langel Ü, Hällbrink M (2016). pH-responsive PepFect cellpenetrating peptides. Int. J. Pharm. 501, 32-38.

23. Cleal K, He L, Watson PD, Jones AT (2013). Endocytosis, intracellular traffic and fate of cell penetrating peptide based conjugates and nanoparticles. Curr. Pharm. Des. 19, 2878-2894.

24. Lundin P, Johansson H, Guterstam P, Holm T, Hansen M, Langel Ü, El-Andaloussi S (2008). Distinct uptake routes of cell-penetrating peptide conjugates. Bioconjug. Chem. 19, 2535-2542.

25. Cory AH, Owen TC, Barltrop JA CJ (1991). Use of an aqueous soluble tetrazolium/formazan assay for cell growth assays in culture. Cancer Commun. 3, 207-212.

26. Foged C, Franzyk H, Bahrami S, Frokjaer S, Jaroszewski JW, Nielsen HM, Olsen CA (2008). Cellular uptake and membrane-destabilising properties of alpha-peptide/beta-peptoid chimeras: lessons for the design of new cell-penetrating peptides. Biochim. Biophys. Acta. 1778, 2487-2495. 
TABLE OF CONTENTS GRAPHIC
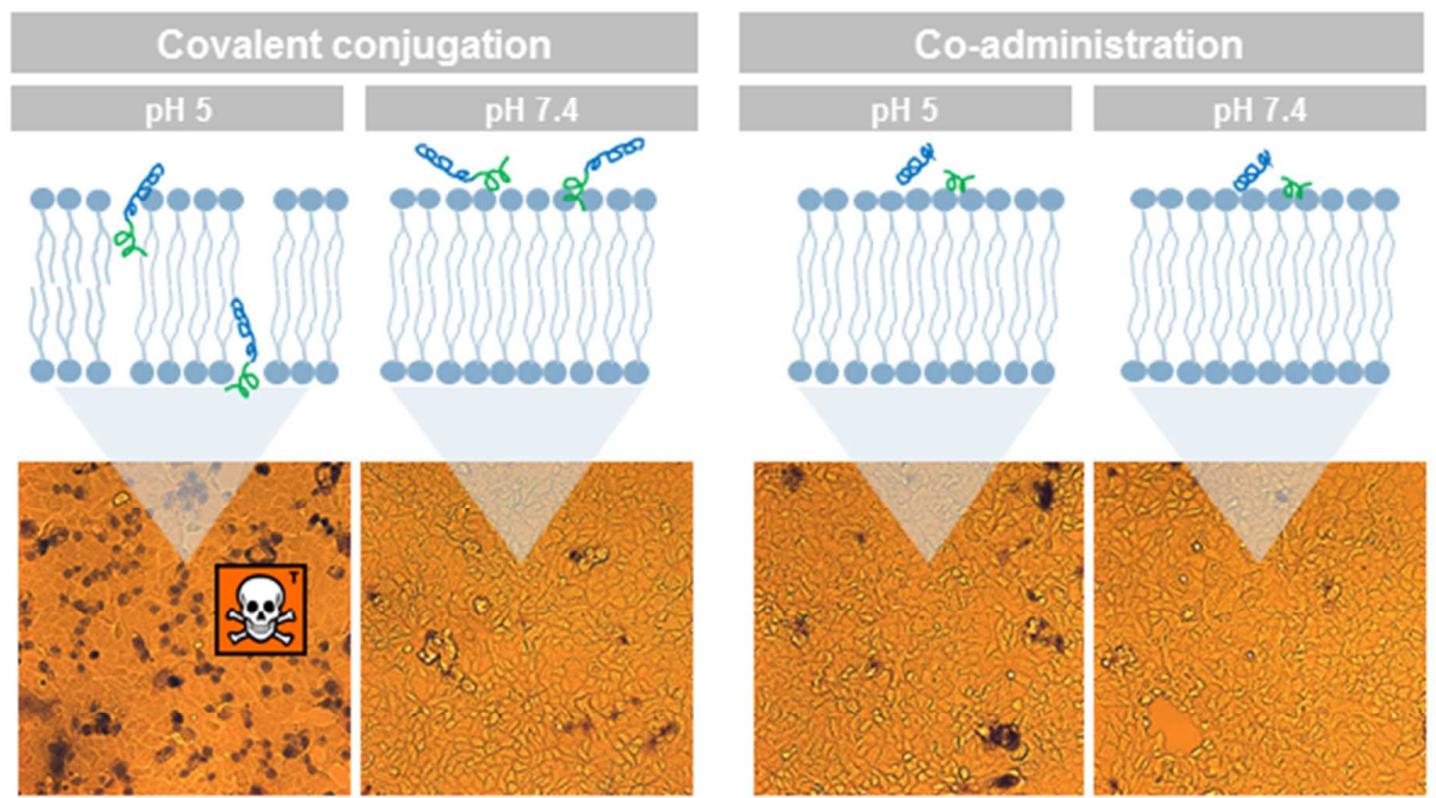


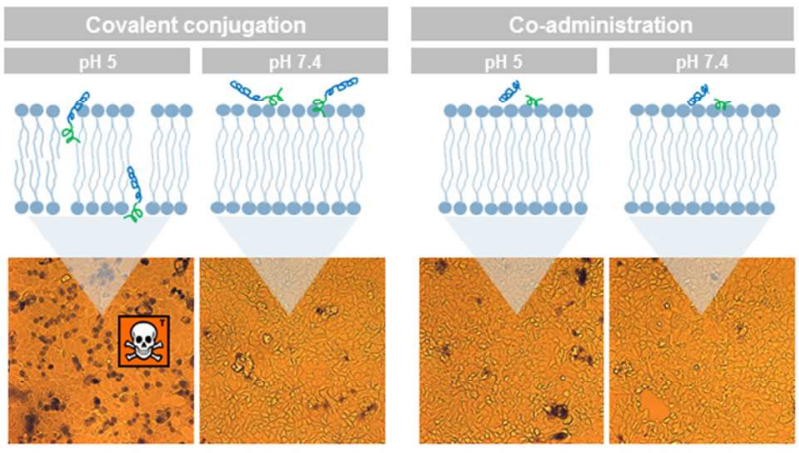

$254 \times 190 \mathrm{~mm}(96 \times 96 \mathrm{DPI})$ 